\title{
A FORMAÇÃO DOCENTE E A NECESSIDADE DE SER PERCEBIDO
}

\author{
Luciana Azevedo Rodrigues* \\ Márcio Norberto Farias ${ }^{* *}$
}

\begin{abstract}
Resumo
Este ensaio visa refletir sobre o enfraquecimento dos estudos desenvolvidos por professores e estudantes em sala de aula e a progressiva fixação na superioridade da comunicação mediada tecnologicamente. Com base na teoria da exploração estético nervosa, desenvolvida pelo filósofo contemporâneo C. Türcke, o texto argumenta que a referida fixação dissimula a expropriação a que professores e estudantes estão sendo submetidos e a angústia de não serem percebidos, em meio à imensa oferta de mercadorias - informações, dados e imagens veiculadas. Por fim, a partir da compreensão da percepção como um produto histórico e social, tal como desenvolvida pelo referido filósofo, o ensaio acena para necessidade da formação de professor se comprometer com a recusa do impulso de poder que chega a exaltar a comunicação mediada e a esquecer que ela só tem sentido quando voltada para a comunicação concreta e direta.
\end{abstract}

Palavras-chave: Exploração. Concentração. Tecnologia. Formação de professores.

\begin{abstract}
This work aims to reflect on the weakening of the studies developed by teachers and students in the classroom and the progressive fixation of

\footnotetext{
* Doutora em Educação pela Universidade Federal de São Carlos (UFSCar). Professora de Filosofia da Educação da Universidade Federal de Lavras (UFLA).E-mail: luazevedo@ ded.ufla.br

** Doutor em Sociologia pela Universidade Estadual Júlio de Mesquita Filho (UNESP). Professor do Curso de Educação Física da Universidade Federal de Lavras (UFLA). E-mail: marxio@gmail.com
} 
communication through technology. Based on the aesthetic nerve exploration developed by the contemporary philosopher $\mathrm{C}$. Türcke, the text claimed that the referred fixation conceals expropriation to which teachers and students have been submitted, and the anguish of not being perceived, due to the huge offer of commodities - information, data and available images. Finally, from the comprehension of perception as a historical and social commodity, such as developed by the philosopher studied, the study shows the necessity of teacher's formation to impact on denying of the boosting of power that gets to the point of highlighting communication mediated and forgetting that it just makes sense when referring to concrete and direct communication.

Keywords: Exploration. Concentration. Technology. Teacher's formation.

Este ensaio visa refletir sobre o enfraquecimento dos estudos desenvolvidos por professores e estudantes na sala de aula sem as mediações do aparato audiovisual e o fortalecimento da fixação dos agentes educacionais na superioridade da comunicação mediada tecnologicamente. Com base na teoria da exploração estético nervosa, elaborada pelo filósofo contemporâneo Christoph Türcke (2010), o trabalho argumenta que o fascínio com que professoras e professores lidam com a comunicação mediada tecnologicamente dissimula para eles mesmos a expropriação que vêem sofrendo à medida que são arrancados das condições que necessitam para se constituírem como sujeitos do processo formativo.

Como um pensamento filosófico que continua a leitura crítica marxiana de que a produção capitalista é constituída por um instrumental que emprega o trabalhador, a obra Sociedade excitada: filosofia da sensação, escrita por C. Türcke em 2002 e traduzida no Brasil em 2010, contém uma interpretação histórica e dialética sobre as mudanças das formas de exploração na sociedade capitalista.

C. Türcke (2010) se detém sobre aquilo que Marx denominou de subsunção formal e real do trabalho, o processo em que o trabalhador individual na manufatura deixou de produzir uma mercadoria e passou a exercer uma parte de sua produção e, na grande indústria, com a máquina, perdeu o domínio que tinha sobre o tempo de produção.

A recuperação da teoria marxiana permite a Türcke (2010) reconhecer no tempo livre a subsunção formal e real, identificadas por Marx no tempo 
de trabalho. Algo que não passou despercebido por Adorno e Benjamin no século XX, apesar de não ter sido apresentado com os mesmos termos do autor de $O$ capital. Com a contribuição de Türcke, é possível ver como a subsunção real do tempo livre se realizou com o surgimento da fotografia e do filme.

Primeiramente, este filósofo recorda que o lazer e a diversão eram vividos de modo entremeado no processo de trabalho com os momentos de divagações e instruções de uns pelos outros. Destaca, ainda, que estes momentos passaram a ser limitados ao fim do dia de trabalho até serem transformados em algo separado dele. Esta divisão - de um lado tempo de trabalho, de outro, tempo livre - expressa aquilo que Marx (1994) abordou como trabalho manufatureiro, e que, conforme Türcke, isolou e submeteu formalmente o tempo livre.

Conforme o filósofo, o impulso industrial, que reorganizou o trabalho ao longo dos séculos XVIII e XIX, alcançou o tempo livre no século XX com o surgimento e o desenvolvimento da fotografia. Nesse processo, o trabalhador fragmentado pela decomposição do trabalho passou a extrair prazer diante da tela ao consumir os choques audiovisuais, que, em suas palavras,

concentra a atenção num ponto, para poder triturar essa concentração através de incontáveis repetições (...). Em seu encanto, o tiro ótico cativa de forma irresistível, pois através de uma repetição permanente ele orienta, de modo gradativo, todo o sensório em si, tanto fisiológica quanto esteticamente, até se tornar imprescindível, como se fosse uma injeção de que o organismo precisa diariamente (TÜRCKE, 2010, p. 266, grifo nosso).

Assim, o tiro que cativa por meio da repetição que relaxa o organismo penetrou o trabalho, com o surgimento e o desenvolvimento do computador no final do século XX. Esta reviravolta produziu um modo pervertido de fusão entre tempo livre e tempo de trabalho, ou seja, o computador, ao reunir divertimento e produção para as pessoas, submeteu-as ainda mais aos choques imagéticos.

Como assevera Türcke (2010, p. 267), “O imperativo categórico 'olhe para cá' próprio das imagens em movimento se transforma ao mesmo tempo em necessidade econômica". Com isso, o olhar enquanto um momento no 
processo de construção do conhecimento é triturado pelo olhe para cá repetidamente se tornando uma espécie de sucedâneo daquele. O olhar repetido para as imagens que se repetem anestesiam e ajudam o organismo a não querer buscar algo além delas. Nas palavras do autor,

onde a atividade de trabalho se transforma em choque imagético, também todos os choques imagéticos e sonoros (...) adquirem a aparência de tarefas de trabalho virtuais.(...)Toda existência começa a depender, de uma forma absurda, de estar presente, de ser percebido ou perceber, de estar esteticamente presente, enfim de estar "aí" (TÜRCKE, 2010, p. 267).

Nesse sentido, podemos ressaltar tanto a relação de professores e alunos com suas caixas de e-mail ou facebook quanto à inquietação vivida no espaço da sala de aula presencial, onde se torna cada vez mais difícil a concentração. No que se refere àquela relação, tem se tornado comum professores e estudantes que se afastam em períodos de férias reconhecerem que a efetividade destas depende de "não acessar" suas caixas de e-mail, ao mesmo tempo em que demonstram um receio de deixar de fazê-lo. Com muito esforço, quando conseguem, tendem a se "apoiar" no choque midiático "puramente" voltado para diversão, que os solicitam cada vez mais com filmes em formatos tridimensionais ou então com formas cada vez mais impactantes de estimulação.

Nesse contexto, a aula presencial tende a evocar a angústia existencial do indivíduo em poder não ser percebido, a qual para ser dissimulada torna o ensino presencial mais um espaço para vivência dos choques imagéticos, ou seja, estudantes e professores sucumbem à grande tela do computador, com a ajuda do Powerpoint e outros softwares mais avançados, que exigem o olhe para cá e proporcionam o relaxamento físico e estético que não visa outra coisa senão o continuar olhando. Quando isso não acontece, a dificuldade de ensinar, de aprender, de se relacionar, e de se permitir ouvir uns aos outros tende a aparecer e, diante delas a irrigação audiovisual, também pode ser realizada individualmente.

A simples condição de estar na aula presencial, que apesar de continuar sendo referida como um espaço mais efetivo de aprendizagem na comparação com a Educação à Distância $(\mathrm{EaD})$, é vivida cada vez mais como um 
empecilho para "conhecer" outros inúmeros lugares, temas, acontecimentos acessíveis on-line. $\mathrm{O}$ estar concretamente num mesmo espaço com outros, nesse caso, na sala de aula, é percebido de modo cada vez mais angustiante tanto por alunos quanto por professores. A angústia de poder não estar estudando aquilo que realmente importa e de não estar acompanhando a imensa quantidade de informações que circulam rapidamente pelo universo on-line é fortemente sentida - uma angústia que remete as pessoas a sua condição humana material-corporal, que insiste em continuar diferenciando-as da reprodutibilidade técnica própria do aparato tecnológico. A vivência do estar na sala de aula, nesse sentido, é progressivamente atacada por essa pressão e, para lidar com isso, o choque midiático que mobiliza tal angústia é chamado a se repetir permanentemente como forma de evitar sua percepção.

Com as dificuldades de viver os limites desse espaço, professores, alunos, conteúdos, mesas de estudos individuais ficam cada vez menores enquanto as salas de aulas se tornam maiores e as versões pequenas de computadores individuais se proliferam "infinitamente". Para os docentes, uma das dúvidas decorrentes do uso dos computadores em sala é: onde o aluno está? na sala, no texto, nas discussões ou nas inúmeras janelas on-line?. Aquela atitude imaginária ou real do discente de se pôr para fora da sala passou a dispor de um "suporte" que a torna desnecessária. Sem perceber, entretanto, o estudante, considera Türcke, passa a sofrer um comando muito mais imperativo que aquele realizado pelos professores mais severos, "o olhe para cá!"

Os professores, por sua vez, para não continuarem com dúvidas sobre a participação ou não de seus alunos, enfrentam o dilema de solicitar que os estudantes não usem o aparato ou obedecer ao comando do "olhe para cá", realizando um movimento que Zuin (2006, p. 947) chama de "conversão da autoridade pedagógica em autoritarismo da imagem". Nesse movimento, a aula presencial também se delineia conforme a agitação produzida pelo choque audiovisual, e a comunicação direta que deveria ser o horizonte da educação mediada tecnologicamente torna-se apagada e desinteressante diante desta. O relato de um professor da Universidade Federal de Lavras sobre uma vivência de ensino na sala de aula com a utilização do skype ensina algo sobre isso. Para participar de uma de suas aulas, uma aluna fez uso do skype, enquanto os demais colegas estavam fisicamente na sala. A participação da aluna pelo skype, no sentido de fazer questionamentos 
e considerações sobre o conteúdo apresentado foi, conforme o professor, espantosamente maior que a daqueles alunos que estavam na sala de aula.

A princípio, esta fala conduz a pensar que o processo educativo se torna muito mais efetivo com o uso dos aparatos tecnológicos. Contudo, a euforia que acompanha este pensamento tende a não problematizar a situação em que a comunicação direta e concreta passa a ser vista como insossa e sem graça. O que tais mídias de comunicação proporcionam evita a recordação de que apesar de todo o progresso da dominação da natureza, cada pessoa vive, sente e pensa a partir de um conjunto de relações determinadas, em sua materialidade corporal concreta, e só consegue experimentar algo numa condição que leve a constituição da memória, num contexto concreto, num lugar determinado e não on-line.

Este processo que nega cada vez mais a natureza, o corpo, avança no sentido de sua exploração e é compreendido por Türcke (2010), como a intensificação do choque imagético sobre a existência, que produz uma nova forma de exploração, denominada por ele de estético nervosa. Tal choque invade os cursos de formação de professores que se expandem predominantemente com a Educação à Distância, ressoando o imperativo social colocado pelo choque imagético: o de que ser percebido depende de estar on-line, no olho da câmera, na tela. E, mesmo no ensino presencial, sem compreenderem esses processos, professores e alunos fazem uso de imagens de violência chocantes na sala de aula como forma de impressionar e ainda filmam suas práticas para reproduzi-las on-line ou no multimídia.

Em vez de considerar esse movimento incessante engendrado com o capitalismo, como a onda que deve ser seguida por todos/as, Türcke (2010) acena para algumas possibilidades de resistência aos efeitos prejudiciais do choque imagético. Na formação de professores, um dos desafios envolve o estudo dos efeitos dos choques para a concentração das pessoas. Para Türcke (2010), o que se vive diante dos choques é uma exploração estético nervosa, que atualiza no nível perceptivo, o que foi engendrado com a condição moderna: a separação do trabalhador dos meios que precisa para se constituir como trabalhador. Para ele, a expropriação do camponês na Inglaterra do século XVI, retratada por Karl Marx (1994), é o que marca o início da modernidade. Ela é evidenciada como a primeira manifestação da permanente convulsão da sociedade capitalista que se fundamenta na separação dos produtores dos meios de produção que necessitam para produzir seus víveres e a si mesmos. 
Para o filósofo, a retirada dos trabalhadores da terra e a impossibilidade deles continuarem significando suas existências a partir das relações que ali estabeleciam, seja com a terra, com as pessoas em torno dela ou ainda, em torno de seus cultos, retirou delas uma constelação que funcionava como fundamento para a percepção delas. Noutras palavras, a separação que tirou o trabalhador rural da terra, o artífice de suas ferramentas, o aristocrata e os cavaleiros de seus bens hereditários privou os seres humanos de relações a partir das quais eles podiam desenvolver a autopercepção e a autoafirmação, privou-os do exercício de repetição que conduz a assimilação e a canalização de excessos de energias em ligações nervosas.

De acordo com Türcke (2010), a privação produzida na condição moderna não permite que o organismo repita o exercício de reviver os choques a que foi submetido, como forma de assimilá-lo, como forma de alcançar um estado em que ele deixe de apavorar e possa ser experimentado prazeirosamente. Türcke 2010, assim como Benjamin, destaca que na modernidade já não haveria condições para corporificar os choques vividos na relação com o mundo externo - pois o ver e o ouvir vivem sob o fogo cerrado dos choques traumáticos. Ademais, para o filósofo contemporâneo se torna ainda mais evidente a condição em que os sentidos são inundados por forças externas que os assaltam sem que estejam preparados para elas, sem que haja o exercício de corporificação desse excesso de excitação em objetos que funcionam como fetiches pré-eróticos, e na sua consequente canalização em ligações nervosas. Türcke $(2010)$ reconhece seguindo a tradição freudiana e benjaminiana de pensamento, que quando isso acontece toda possibilidade de controle do organismo a partir do trabalho que permite essa assimilação fica comprometida. Chamada por Türcke de compulsão a repetição ritualística e identificada por meio de objetos fetiches como ossos sagrados, peles, pedras, árvores, lanças, escudos etc., tal repetição corresponde ao processo de assimilação dos choques vividos pelo ser humano.

Ao se apoiar em Freud para falar da produção moderna de uma privação pré-erótica, Türcke (2010) se refere à perda de

uma constelação singular, na qual víveres secularmente praticados e adquiridos, a aproximação corpórea com o aparentado, uma rígida hierarquia social, assim como rituais e costumes internalizados na esfera mais íntima se amalgamaram em conjunto. Essa constelação 
foi pressão, mas também, em certa medida, amparo, uma vez que seus componentes se apoiavam mutuamente e se referiam uns aos outros (TÜRCKE, 2010, p. 242) .

Essa privação lesou todo um sistema de relação e referência que proporcionava certa assistência a tais reveses. (...) É como se o sutil filamento que ligava tudo, de forma invisível, fosse extraído de seu tecido sólido, tanto na dimensão social quanto na neuronal (TÜRCKE, 2010, p. 243).

Esta privação precisa ser reconhecida hoje como algo que tem se prolongado e se aprofundado, inclusive nas instituições de ensino que durante séculos estiveram protegidas das leis de mercado e da troca trazendo desafios ainda maiores para a formação de professores, que historicamente foi e ainda é considerada inferior quando comparada a outras formações, tal como podemos ver no texto do filósofo frankfurtiano Theodor Adorno "Tabus acerca do magistério".

De um lado estão lançadas as ferramentas para que qualquer pessoa, em qualquer tempo e espaço, em qualquer condição realize seu curso de licenciatura, inclusive aquelas que não desejam e mesmo assim precisam responder a pressão de concluir um ensino superior. Desse modo, torna-se muito comum qualquer pessoa, querendo ou não, se tornar professor, pois para tal são levadas a acreditar que basta possuir um computador conectado a rede Internet. De outro lado, professores e alunos dos ensinos presenciais experimentam aquela separação de produtores e meios de produção de diferentes formas, sendo levados a concorrer a editais públicos ou privados para garantir recursos ou a chancela para a realização de seus estudos, e a se contentar com a felicidade de elevar sua produtividade em prazos cada vez mais curtos. Nem professores, nem estudantes de instituições públicas estão protegidos disso. Pelo contrário, é como se eles precisassem se lançar para fora de qualquer relação de estudo continuada para atender as demandas de projetos que lhes são permanentemente oferecidas na forma de editais de modo que possam angariar verbas e produções que os tornem reconhecidos como sérios captadores de recursos, ao mesmo tempo em que suas vidas são afastadas de qualquer sensação de que poderiam existir outros modos de investimentos para realização de um trabalho que também é vida e que, nesse sentido, reluz a formação. A atual condição também referida por Türcke (2010) como estetização da vida e do trabalho afasta ainda mais as pessoas da percepção de que continuam vivendo 
sob condições de exploração, e reforça a ideia de que qualquer um pode ser vencedor e perdedor, pois todos se encontram diante de uma grande e neutra roleta da vida, fazendo suas apostas com mais ou menos sorte.

Além de recuperar a teoria marxiana da exploração e dizer que ela tornou evidente que a relação de compra e venda da força de trabalho oculta a mais desavergonhada exploração - a medida que a força de trabalho que produz valor jamais recebe pelo valor produzido e sim pelo valor que possui - Türcke sustenta que a exploração física não se restringe à mais-valia que não é paga. Diz ele que:

o capitalismo transformou a própria situação da exploração, sendo que o quão profundamente ela foi transformada só pode ser mostrado posteriormente, pois a exploração foi transformada no seu estado estético (...) com o expulsar das capacidades humanas de seu contexto de desenvolvimento e adequação para a realização de atividades de trabalho isoladas, pôs-se em movimento uma conversão técnica do organismo como um todo (TÜRCKE, 2010, p. 274).

Nessa passagem em que a exploração estética é compreendida a partir da desapropriação dos sentidos do contexto, no qual eles se constituíram, e da ocupação dos mesmos com estímulos isolados, ressoa aquela expulsão que Türcke evidencia como início da modernidade, ou seja, a desapropriação do trabalhador da terra, o do artífice em relação as suas ferramentas, a do aristocrata e dos cavaleiros em relação aos seus bens hereditários, a do álcool destilado em relação ao meio de fermentação que o produziu, a do instante da fotografia do contexto que lhe atribui sentido, a do mercado em relação ao sagrado que lhe conferia a busca pela pacificação. Em suas palavras:

Quanto menos a força muscular foi aplicada às máquinas colossais, quanto mais as pontas dos dedos e os movimentos oculares foram motora e refinadamente alinhavados a aparelhos microeletrônicos, mais se destaca para qual direção a transformação da exploração aponta: para exploração da concentração (TÜRCKE, 2010, p. 274).

Esse processo de alinhavamento é identificado pelo autor como a esteira industrial capaz de desenvolver novos níveis de complexidade para assimilar 
e, ao mesmo tempo, de simplificar as operações requeridas pelas máquinas, permitindo tanto uma diminuição de tempo de incorporação daquelas operações pelos seus usuários quanto de produção alcançada por meio delas.

O que aí se destaca é a perda do exercício de relações entre os órgãos dos sentidos, a expropriação do contexto no qual surgiram e conferia significado ao que era sentido. Diante da tela, dos milhares e infinitos lugares que as pessoas podem estar, um processo de dispersão, decomposição e expropriação dos sentidos é euforicamente exercitado - o consumo dos choques audiovisuais. Contudo, o filósofo adverte que a exploração estético nervosa nunca ocorre de modo isolado, mas sempre como uma torrente de estímulo que intensifica o esvaziamento pela superlotação de estímulos e que liquidifica a abstração por meio do concreto.

Nesta direção, Türcke (2010, p. 278) considera que "quanto mais complexo é um trabalho, mais se torna imprescindível que a concentração, que lhe é exigida, seja a do próprio trabalhador". Desse modo, quanto mais os sujeitos exercitam a própria concentração, mais isso explicita a complexidade dos trabalhos que conseguem realizar e, assim, a menor possibilidade de que eles sejam substituídos. Daí o autor afirmar que a exploração estético nervosa é o lado interno da econômica, pois tornar-se concentrado ou concentrar-se depende então da complexidade ou simplificação do trabalho.

A complexidade que exige o concentrar-se, no contexto em que a simplificação vem se generalizando, tende a ser recusada também nos cursos de formação de professores. Daí a necessidade de compreenderem os efeitos desse processo simplificador que concentra a percepção humana em vez de aplicarem o referido alinhamento, inclusive com o objetivo de superar a falta de atenção e a desconcentração identificadas em sala de aula. Em outras palavras, como forma de vencer a falta de atenção nas salas de aula, especialmente para a leitura de um texto complexo, alguns cursos de formação docente têm recorrido aos aparatos audiovisuais, às imagens fílmicas no computador, sem saber que isso pode reforçar os estímulos isolados dos sentidos humanos. Dessa forma, em vez de buscarem um ater-se, de tornar sedentárias as representações e imagens, o que se vivencia é a substituição permanente de representações e imagens fugazes.

Com a referida perspectiva de alinhamento, a formação de professores não dispõe de condições para o desenvolvimento da percepção, mas sim de recepções que são cada vez mais pontuais e que dispensam o desen- 
volvimento da percepção do próprio indivíduo como sua percepção. Sem concentração, sem percepção das próprias recepções e representações como suas, professores e estudantes confrontam-se com situações como a inexistência de autoria e talvez o plágio seja uma expressão dessa dificuldade de perceber o que é próprio. Pois, apesar de se falar tanto em individualidade, torna-se difícil realizá-la quando as demandas de produção cada vez mais aceleradas e "diversificadas", não deixam espaço para a percepção do que é percepção, representação e pensamento do próprio sujeito, mas requerem respostas que continuam exteriores ao eu, tais como as extremidades do corpo - dedos e olhos.

Desse modo, com seu movimento ininterrupto, o que os choques imagéticos não permitem existir é a retenção, um espírito que exercite "um contato corporal com as ideias" (ADORNO, 2010, p. 21).

Depois de teorizar sobre o movimento histórico no qual o sensório humano se constituiu, se modificou e vem sendo enfraquecido, Türcke (2010) vislumbra práticas que se tornam vitais ao desenvolvimento da percepção e do pensamento no contexto atual. Nelas, o autodesperdício assume extrema importância para a conversão das imagens audiovisuais em vacina e para a produção de imagens reflexivas. O filósofo e professor em Leipzig admite que não é possível falar em abstinência em relação a irradiação audiovisual devido tanto a questão econômica quanto a neurológica, por isso propõe que diante dela as pessoas consigam dosar o seu consumo, alimentar o organismo com pequenas doses de substâncias tóxicas, de tal modo que possam dominar os choques audiovisuais e não serem dominadas por eles. Nesse sentido, mesmo depois de reconhecer que a transcrição de textos e fórmulas tem suas origens na chamada pedagogia tradicional, baseada na memorização dos conteúdos, Türcke (2010) afirma que sob as condições gerais de agitação este modo de reter pode tornar-se

uma medida de concentração motora, afetiva e mental, de recolhimento interior e, por que não dizer, de recordação, ou seja, uma medida não muito diferente daquilo que, na linguagem teológica, se chama devoção (TÜRCKE, 2010, p. 305).

Além desse exercício de dedicação, o filósofo se refere à importância de viver sensações profundas, que não se dão pelo grito - imagens velozes 
e violentas - mas por seu caráter simbólico, de imagem-pensamento. Nesse sentido, as sensações profundas enquanto frágil luzir de algo melhor não podem ser confundidas com as sensações que alimentam o impulso de poder fazer mais, ouvir mais, falar mais, ter mais, pois o entusiasmo que elas mobilizam só pode ser alimentado com mais doses de imagens audiovisuais, seja na educação a distância ou na presencial. Dessa forma, talvez seja frutífero pensar que a utilização das imagens audiovisuais na formação de professor comprometida com a emancipação humana precisa rever aquele impulso de poder que chega a exaltar a comunicação mediada e a esquecer que ela só adquire sentido quando voltada para a comunicação imediata concreta e direta - a única capaz de levar homens e mulheres a não só se comunicarem mas, fundamentalmente, serem capazes de juntos elaborarem, assimilarem seus medos e vislumbrarem um mundo melhor.

\section{Referências}

ADORNO, T. W. Tabus acerca do magistério In: . Educação e emancipação. Tradução de Wolfgang Leo Maar. Rio de Janeiro: Paz e Terra, 1995. p. 97-117.

. Teoria da semiformação. In: PUCCI, B. ZUIN, A. A. S. LASTÓRIA, L. A. C. N. Teoria crítica e inconformismo: novas perspectivas de pesquisa. Campinas: Autores Associados, 2010. p. 07-40.

BENJAMIN, W. Sobre alguns temas em Baudelaire. In: . Charles Baudelaire, um lírico no auge do capitalismo. Tradução de José Carlos Martins Barbosa e Hemerson Alves Baptista. 1., ed. São Paulo: Brasiliense, 1989. $271 \mathrm{p}$.

MARX, K. O capital: crítica da economia política. Tradução de Reginaldo Sant'anna. Livro 1, 14., ed. Rio de Janeiro: Editora Bertrand, 1994.

TÜRCKE, C. Sociedade excitada: filosofia da sensação. Tradução de Antonio A. S. Zuin, Fabio A. Durão, Francisco C. Fontanella, Mario Frungillo. Campinas: Editora Unicamp, 2010. 
ZUIN, A. A. S. Educação a distância ou educação distante? O programa universidade aberta do brasil, o tutor e o professor virtual. Educ. Soc., Campinas, v. 27, n. 96, p. 935-954, Out. 2006. Disponível em <http://www.scielo.br/scielo. php?script=sci_arttext\&pid=S0101-73302006000300014\&lng=pt\&nrm=iso $>$. Acesso em: 29 Jul. 2013.

Data de registro: $16 / 02 / 2014$

Data de aceite: 22/10/2014 